\title{
IOT Based School Child Tracker System
}

\author{
Shruti Anant Tiwarkar, Aishwarya Dinkar Ghare \\ Shaila Suresh Bhumannavar, Gaurav Kishor Kshirsagar. \\ Guided by Prof. Pallavi Patil \\ JSPM Narhe Technical Campus
}

\begin{abstract}
In today's world the number of child kidnapping cases are increasing and the count of these is also increasing day by day. So the safety of children become the topic of concern. Despite the strict majors taken for children safety by the authorities the crimes over children are increasing on significant amount. To restrict these crimes it is important to enhance security for children. This paper proposed a system which focus on children safety by tracking them and providing the live location of child with the help of GPS module and sending information through SMS notification. Each student possesses an RFID tag on his own ID card which is useful for identifying the student and GPS module for tracking their live location. It allows the parent to get their child's location on a real time map and its marked attendance at school. Also display the attendance of particular student to the teacher. The system consists of two sides' teacher side and parent side.
\end{abstract}

Keywords:- Internet of Things (IoT), RFID, Global Positioning System (GPS) location tracking, SMS notification.

\section{INTRODUCTION}

Now-a-days school children travel through school buses, vans or by other transport vehicles. But due these kidnapping cases the safety of these children become top priority. So to avoid this problem some schools develop a system called School Bus Tracking System. This system only track the school bus and marks the entry and exit of the child. But what about those children who travel individually. The safety problem remain same for those children. Here this paper proposed a system for the safety of children.

A system which identify the child by RFID tag which contain the information of child and mark the attendance. Also the GPS module which is placed on the ID card gives the live location of the child and send the information through SMS notification to parents on their android application.

By using this system, it is possible to analyze the location of child and information about marked attendance of child. Also solved the safety issue.

\section{MOTIVATION}

These days due to school child kidnapping and other crime cases regarding the children the safety of children worries the parents. There is no such a system which will track the individual child and notify their parents. So here to overcome this problem we are providing the IoT based system as a solution.

\section{PROBLEM DEFINITION}

Designing the system for the parents that will help to track their child between their home to school and vice versa. The system will also make the attendance of the student. The attendance and the location will be notify on Android application to the Parent.

\section{METHODOLOGY}

The aim of the system is to provide safety by creating a system for individual child which will track the location of child and notify their parent. Here whole system is implemented on child's ID card which contain RFID and GPS module. RFID tag is used for identification purpose which contain particular child's information and mark the attendance on the cloud. Also GPS module for live tracking purpose. So it shows the live tracking of child from his home to school and vice versa. Here it also sends the SMS notification to the parents on their android application.

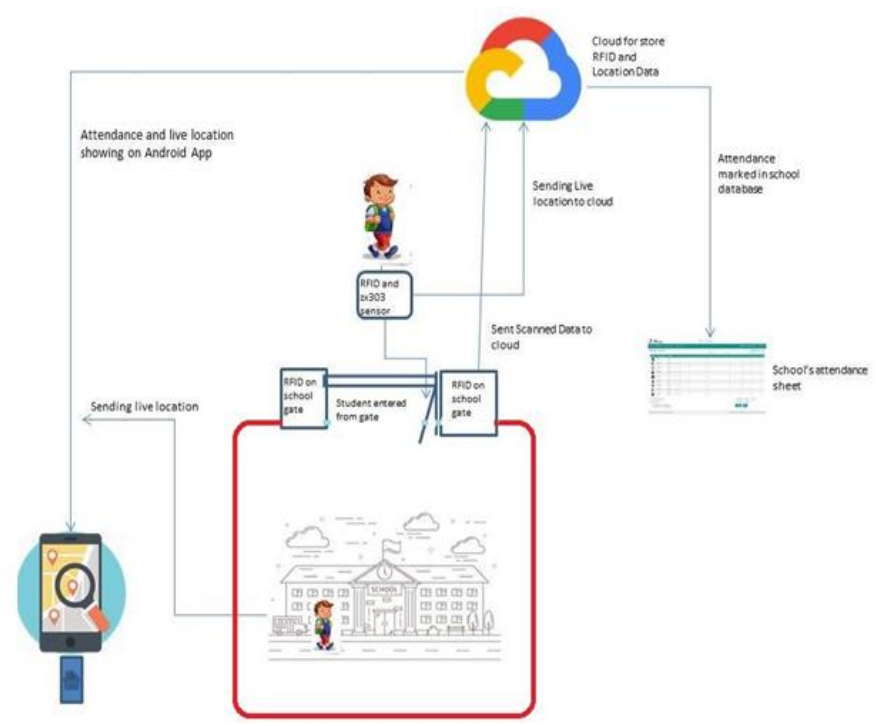

Fig 1:- System Architecture 
ISSN No:-2456-2165

\section{WORK}

Basically the system is divided into 3 modules:

$>$ RFID Scanning

$>$ Location Identification through GPS

Notification

\section{A. Working of RFID Scanning:}

* What is RFID?

RFID or Radio Frequency Identification System is a technology based identification system which helps identifying objects just through the tags attached to them, without requiring any light of sight between the tags and the tag reader. All that is needed is radio communication between the tag and the reader.

Three Main Components of a RFID System:

A RFID tag: A RFID tag consists of a microchip built by silicon. It is attached to an antenna and embedded on a substrate and wrapped in different substances like plastic or glass veil and with an adhesive on the back side to be attached to objects.

$>$ A reader: It consists of a scanner with antennas to transmit and receive signals and is in charge for communication with the tag and receives the information from the tag itself.

$>$ A Processor or a Controller: This can be any host system with a microprocessor or microcontroller. It receives the sensed data and processes it.

- Here the RFID tag is placed on ID card and the RFID reader is placed on the school gate.

- When the child scan the RFID tag on the reader it will scan the date from the tag and send it on the cloud.

- Like this the attendance of the child get marked in binary form 1 as present and 0 as absent.

- Then the data get fetched from the cloud and shown to the parents on the Android application.

- Also mark the attendance in the school database.

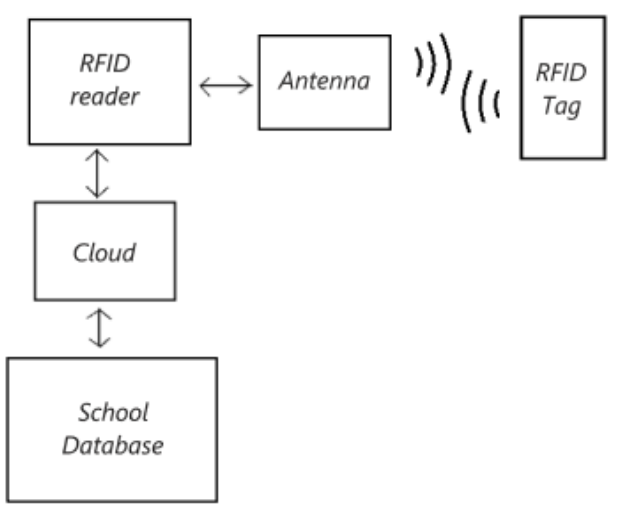

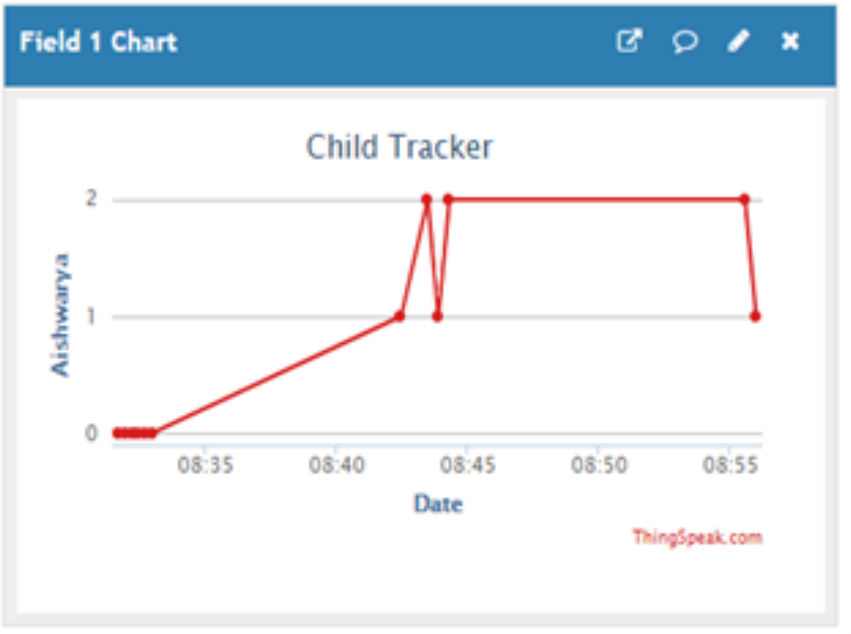

Fig 3:- Data Posted on CLOUD “ThingSpeak"

B. Working of Location Identification through GPS:

Here GPS module which is on child's ID card track the location from home-school-home. Also by using GSM it sends the SMS notification to parents. We used 2G SIM card in this experiment, it permits to send SMS to parent authority. It functions as a mobile phone for the purpose of sending SMS through a radio waves. It is slim and compact in size. Low power consumption is major advantage to choose this one.

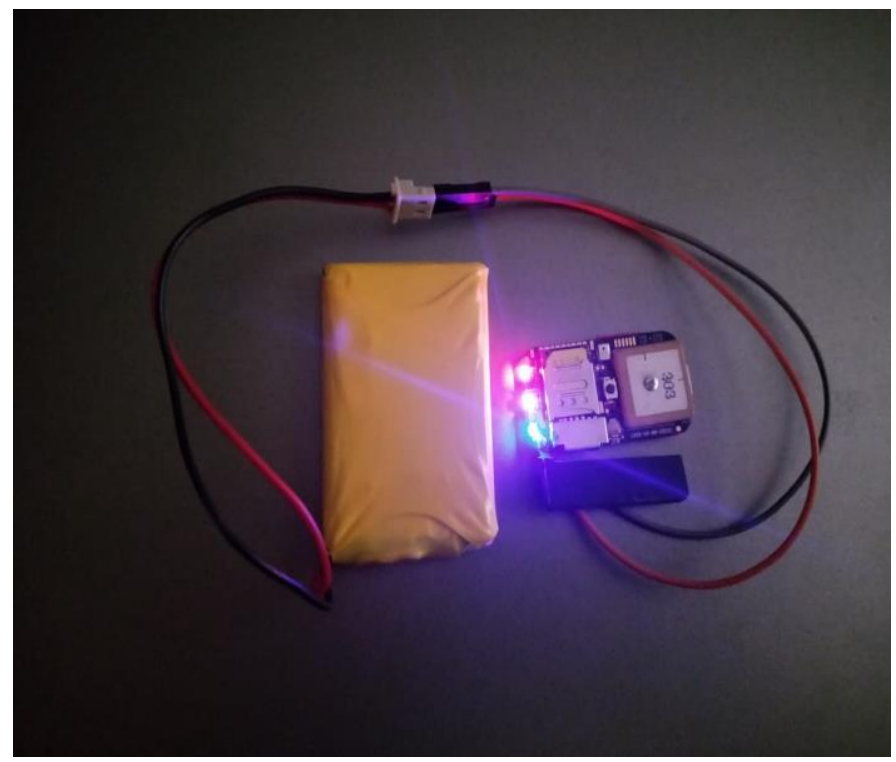

Fig 4:- GPS Device

Fig 2:- RFID Scanning 


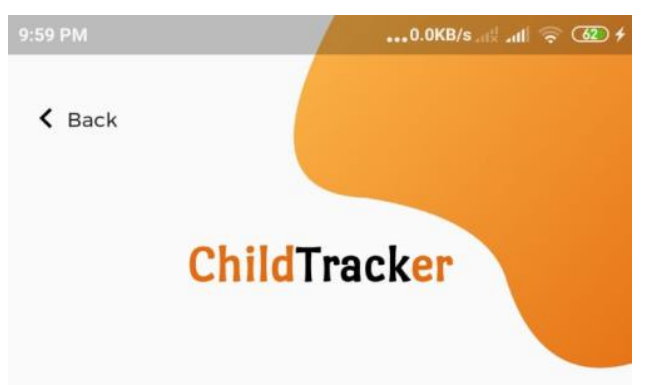

Email id

Password

Login

Forgot Password?

Don't have an account? Register

Fig 5:- Login Page

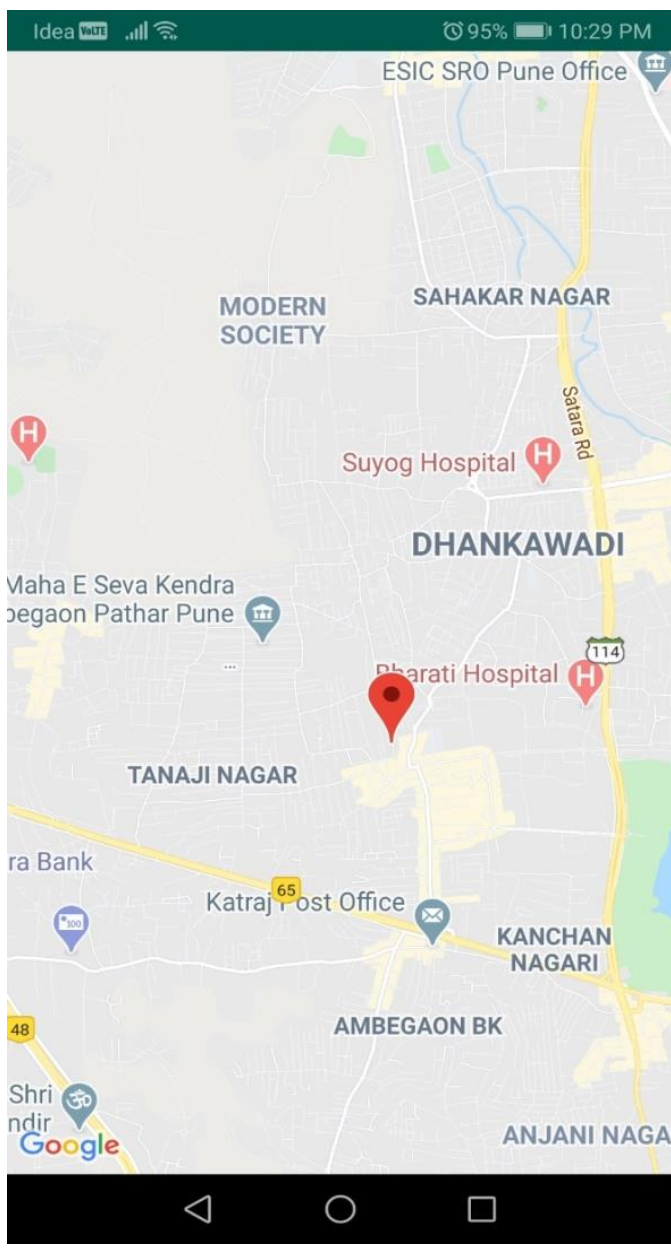

Fig 6:- Current Location

\section{Notification:}

$>$ Display the attendance of particular student to the teacher.

This becomes analyzing data easy for the teacher.

$>$ This system is capable of notifying parent through SMS once the child enters/leaves the school.

$>$ Also using this system parents can track the live location of child.

\section{ANDROID APPLICATION}

An android application provide the marked attendance through RFID also live tracking by GPS. This application basically developed by using android studio and also data get fetched from ThingSpeak to display on it.

\section{A. Result:}

Here as a result we have developed a system which helps to keep the track of child's whereabouts. Using RFID system it detect whether the child reached or not at school. The message get sent simultaneously to the parents and the School. Also the details of the child attendance updated in the school database. The GPS is used for live tracking of the child if it goes other than the usual Path and it will display to the parent through android application.

\begin{tabular}{|c|c|}
\hline PARAMETER & OUTCOME \\
\hline $\begin{array}{c}\text { RFID Module } \\
\text { (Attendance) }\end{array}$ & Student is present /absent \\
\hline GPS Module & $\begin{array}{c}\text { Students current location } \\
\text { using ID through android } \\
\text { application }\end{array}$ \\
\hline Notification & $\begin{array}{c}\text { In/Out status of student to } \\
\text { parent }\end{array}$ \\
\hline
\end{tabular}

Table 1

\section{CONCLUSION}

The safety of the school children during the daily outing become an issue of concern. Here our developed system has helped to reduce this problem.

\section{FUTURE SCOPE}

In future for more accurate result we can integrate fingerprint scanning also.

\section{ACKNOWLEDGEMENT}

We express our sincere thanks to Professor Pallavi Patil (Professor JSPM Narhe Technical campus) for guiding us throughout the project. 


\section{REFERENCES}

[1]. Abha Damani, Hardik Shah and Krishna Shah (2015). "Global Position System for Object Tracking". International Journal of Computer Applications (0975 -8887) Volume 109 -No. 8

[2]. Hind Abdalsalam Abdallah Dafallah (2014). "Design and Implementation of an accurate real time GPS tracking system". The Third International Conference on e-Technologies and Networks for Development (ICeND2014).

[3]. Khairul Shafee Kalid and NabihahRosli (2017). "The Design of School Children Identification and Transport Tracking System". International Conference on Research and Innovation in Information Systems (ICRIIS).

[4]. Hamad Alqahtani and Hasan Al-Sakran (2016). "Using Internet of Things for Building Smart Student Tracking System".

[5]. Amit Bhoyar and Rajeev Varma (2018). "GPS Based Real Time Vehicle Tracking System for Kid's Safety using RFID and GSM". International Journal of Advance Research, Ideas and Innovations in Technology, www.IJARIIT.com. 